\title{
Effect of Extreme Rainfall Intensity on Matric Suction and Ground Movement
}

\author{
Muhammad Hazwan Zaki ${ }^{1}$, Mastura Azmi ${ }^{1, *}$, Siti Aimi Nadia Mohd Yusoff ${ }^{1}$, Muhd Harris Ramli $^{1}$ and Mohd Azril Hezmi ${ }^{2}$ \\ ${ }^{1}$ School of Civil Engineering, Engineering Campus, Universiti Sains Malaysia, 14300 Nibong Tebal, Pulau Pinang, Malaysia \\ ${ }^{2}$ School of Civil Engineering, Universiti Teknologi Malaysia, 81310 UTM Johor Bahru, Johor, Malaysia
}

\begin{abstract}
Increased intensity of rainfall events due to extreme climate change has led to the substantial increase in the occurrence of disasters, especially in a tropical-climate country such as Malaysia. Rainfallinduced landslide has become one of the most common types of disasters, and its triggering factors are still uncertain and impossible to predict. In this study, the effect of extreme rainfall intensity on groundwater behaviour is addressed through laboratory-scale testing. The adopted rainfall intensity is $60 \mathrm{~mm} / \mathrm{h}$, which was the heaviest hourly rainfall intensity recorded in Sarawak on 3rd January 2016 and $80 \mathrm{~mm} / \mathrm{h}$, which was the corresponding value recorded in Penang on 10th October 2016. The simulation is conducted on four cases. The simulated rainfall exhibits a duration of $6 \mathrm{~h}$. In addition, the overall trend of the matric suction measurement and soil moisture in all cases is discussed on the basis of the results obtained from laboratory studies. After the rain simulator stopped, the matric suction decreases, and it remains stagnant, followed by a significant drop in the reading. For all cases, failure occurs, albeit at different times with different volumes of mass wasting.
\end{abstract}

\section{Introduction}

Natural disasters such as heavy snowstorms, extreme heat waves, landslides, floods, tsunamis, and heavy rainfall, as well as increased sea levels, affect human security [1]. Different factors trigger slope failure, such as slope morphology, groundwater movement, seepage, and earthquakes. However, Suhaila and Jemain [2] reported that rainfall contributes to slope failure for a majority of events in Malaysia.

\subsection{Physical modelling}

In this study, the effect of extreme rainfall intensity on slope stability is examined by using a physical model. A physical model is used to model and control parameters and characterize variables. Few slope physical models were examined in past studies. Ling Hoe et al. [3] conducted an experiment using a centrifuge model, which produced an acceleration of $200 \mathrm{~g}$ with a payload of $1,500 \mathrm{~kg}$ at Columbia University. Tohari et al. [4] conducted an experiment with a sand slope tank of $3 \mathrm{~m}^{3}$ and a slope height of $1 \mathrm{~m}$.

\subsection{Rainfall simulator}

To model rainfall by physical modelling, a suitable rainfall simulator must be adopted to ensure the similarity of the simulated rainfall to the natural rainfall. During the selection of the rainfall simulation, few desirable characteristics are carefully evaluated: (a) accurate reproduction of the natural rainfall drop size and energy produced; (b) continuous and uniform application of rainfall over an area; and (c) application ability to various intensities and durations of rainfall [5].

The rainfall simulator can be categorized into pressurized and non-pressurized rainfall simulators. In the non-pressurized simulator, the drop is produced by the hypodermic needle under the influence of gravity to achieve the terminal velocity. In case of the pressurized simulator, pressurized nozzles are used with varying pressures to imitate natural phenomena. However, in the pressurized simulator, soil erosion may occur due to the excess flux created by the pressure, while the nonpressurized simulator is capable of controlling the drop size, but it requires a certain height to achieve the terminal velocity [6]. In this study, the non-pressurized rainfall simulator is adopted due to its capability to control the size and intensity of the raindrop to avoid any excessive slope surface erosion that contributes to the decrease in slope stability.

\section{Methodology}

\subsection{Rainfall analysis data}

In determining the extreme rainfall intensity, two methods, i.e., direct adoption and rainfall analysis, respectively, are adopted to select the rainfall intensity that was classified to be in the extreme range. Table 1 summarizes the comparison of the baseline data reported

\footnotetext{
Corresponding author: cemastura@usm.my
} 
by the Department of Irrigation and Drainage (Malaysia) and a previously reported study [7].

Table 1. Comparison of rainfall intensity classification.

\begin{tabular}{|l|c|l|c|}
\hline \multicolumn{2}{|c|}{ Yakubu et al. [7] } & \multicolumn{2}{c|}{$\begin{array}{c}\text { Department of Irrigation \& } \\
\text { Drainage, Malaysia, 2017 }\end{array}$} \\
\hline $\begin{array}{c}\text { Rainfall } \\
\text { Intensity } \\
\text { Classification }\end{array}$ & $\begin{array}{c}\text { Rainfall } \\
\text { Intensity } \\
(\mathrm{mm} / \mathrm{h})\end{array}$ & $\begin{array}{c}\text { Rainfall } \\
\text { Intensity } \\
\text { Classification }\end{array}$ & $\begin{array}{c}\text { Rainfall } \\
\text { Intensity } \\
(\mathrm{mm} / \mathrm{h})\end{array}$ \\
\hline Low & $<4$ & Light & $1<\mathrm{I}<10$ \\
\hline Medium & $4<\mathrm{I}<15$ & Moderate & $10<\mathrm{I}<30$ \\
\hline High & $15<\mathrm{I}<30$ & Heavy & $30<\mathrm{I}<60$ \\
\cline { 1 - 2 } Very High & $30<\mathrm{I}<60$ & Very & $>60$ \\
\cline { 1 - 2 } $\begin{array}{l}\text { Extremely } \\
\text { High }\end{array}$ & $>60$ & Heavy/Extreme & \\
\cline { 1 - 2 }
\end{tabular}

\subsection{Rainfall analysis}

For this method, the rainfall data from Kolam Air Bersih, Pulau Pinang rain gauge station for the 2016 North East Monsoon (NEM) season are plotted in the hyetograph. The analysis is performed by the determination of the highest hourly rainfall during that period. The hyetograph in the analysis is selected on the basis of the peak rainfall intensity distribution, where the highest single peak for a certain period is selected.

\subsection{Soil physical characterization}

Mining sand is the soil used in physical modelling, which is collected from a mining area in Kampung Kuala Trong, Taiping, Perak. The sample is collected from a depth of $0.5 \mathrm{~m}$ from the soil surface as disturbed sample. The sand used in the model is sieved, and only the sand that passes through a $3.35-\mathrm{mm}$ sieve and is retained on a $2-\mathrm{mm}$ sieve is used in the model. Figure 1 shows data corresponding to the soil physical characteristics as reported by Azmi et al. [8].

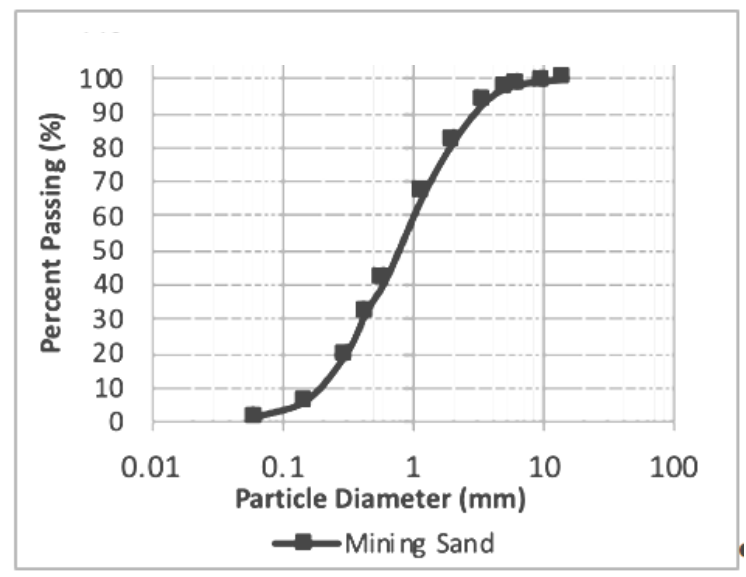

Figure 1. Soil particle size distribution [8].

\subsection{Soil-water characteristic curve}

The soil-water characteristic curve (SWCC) can be used to estimate unsaturated soil parameters, such as unsaturated shear strength and unsaturated soil permeability. The hydraulic function in the Geostudio software is estimated by the Fredlund-Xing-Huang equation. SWCC is notable for the numerical analysis of the seepage and analysis of the slope stability. Figures 2 and 3 show the SWCC and estimated hydraulic conductivity function for this study, respectively.

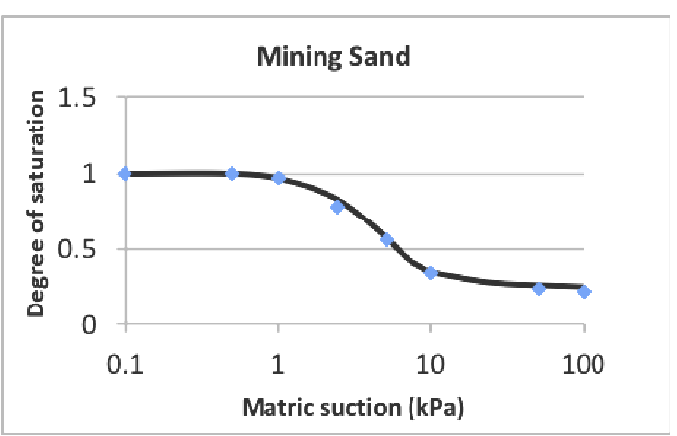

Fig. 2. SWCC of the mining sand used in the physical model.

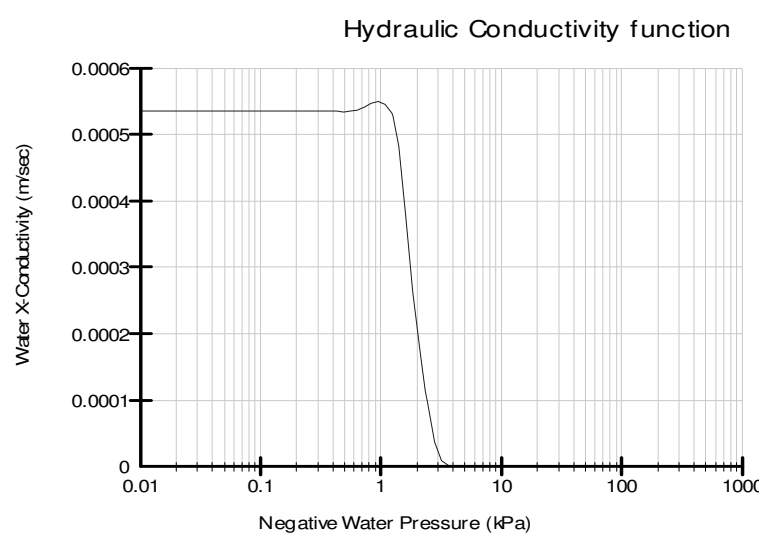

Fig. 3. Estimated hydraulic conductivity function in Geostudio.

\subsection{Physical model}

The test facility and general arrangement of the slope model box are illustrated in Figure 4. The physical model is divided into three main systems: no. 1 is a model box, no. 2 is a water control system (groundwater level) and no. 3 is a rainfall simulator system, including a huge tank water equipped with a water pump.

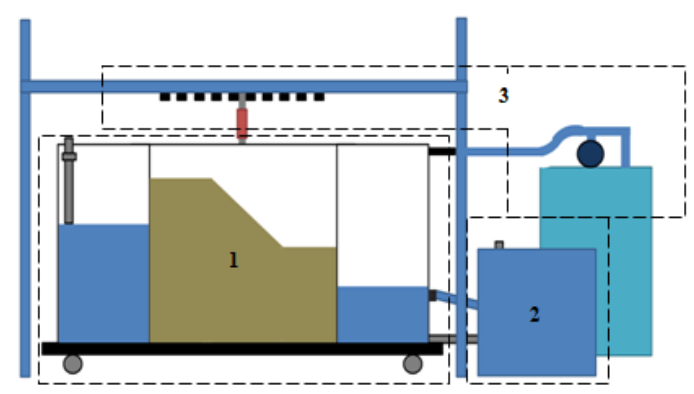

Fig. 4. (1) Rainfall simulator, (2) Sand slope model, (3) Water circulation system. 
The main element of the test is the model box. The model box has an inside dimension of $1 \mathrm{~m} \times 1 \mathrm{~m}$ in the side view and it is $1 \mathrm{~m}$ deep. The next element in this study is groundwater systems. Two other boxes, also known as groundwater level (GWL) boxes $(1 \mathrm{~m} \times 0.5 \mathrm{~m}$ in the side view and it is $1 \mathrm{~m}$ deep), were built at both sides of the rectangular flume and were equipped with a valve to observe and control the groundwater level. A big valve was placed on the sidewall adjacent to the toe of the slope at an elevation of $90 \mathrm{~cm}$ from bottom and was used to draw water from main box to the GWL box. In the soil container, a finite slope with height of $0.7 \mathrm{~m}$. The slope was constructed uniformly, using plywood and tamper, and it was formed in three layers. Prior to the model slope experiment of $60^{\circ}$ inclination, the preceding experiment was performed in $40^{\circ}$ inclination. This was done to verify the seepage behaviour of rainfall and its effect on the model slope. A water control system was designed to regulate the rise and drawdown of water in the slope model. The water level control system consisted of a water storage tank, a valve equipped with plastic tube to draw the water from slope model boxes to the GWL boxes then to the water storage tank and a water pump inside water storage tank to pump the water from outlet to inlet. The groundwater can be elevated or lowered to any level using a water pump. Lastly, another important element in this study is the rainfall simulator systems. The rainfall simulator was designed with the following components: drip, flow meter, water delivery system, water pump and water tank. Drips were selected based on an ability to distribute drops uniformly and produce drop sizes similar to natural rainfall. The flow meter was used to monitor rainfall intensity. The water delivery system was designed to provide adequate flow to the risers while maintaining a suitable operating pressure. Finally, a water tank equipped with a water pump was used to pump water from the water tank to produce rain. A rainfall simulator was set approximately $1.7 \mathrm{~m}$ above the surface of the model slope. An intensity of artificial rainfall of $80-120 \mathrm{~mm} / \mathrm{hr}$ is characterised as heavy rainfall in Malaysia. In addition, saturated permeability was considered. The ponding slope surface would have happened because the rainfall intensity was greater than $30 \mathrm{~mm} / \mathrm{hr}$. The artificial rainfall would introduce surface erosion and the formation of gullies. The amount of water flowing into the 100s rain drip was carefully controlled, and it was monitored using a flow meter.

An extensive instrumentation plan was designed to assess the changes in hydrological and geo-mechanical responses of the slope during artificial events. Water content was measured using a time-domain reflectometer (TDR) sensor. The probe for the TDR sensor was the EC-5 from Decagon Device Inc., and its dimensions are $8.9 \mathrm{~cm} \times 1.8 \mathrm{~cm} \times 1.7 \mathrm{~cm}$. The data logger used was the GP2 from Delta -T Device measuring every 1 minute. Meanwhile, matric suction was measured by using a SWT5 Tensiometer also from Delta-T Device, which consists of a sensor body and a 70-mm-long shaft fully saturated with water. A porous stone is attached at the edge of the shaft. The thickness of the shaft is $5 \mathrm{~mm}$. Lastly, because contact of the porous stone with the unsaturated soil causes inevitable desaturation, calibration of the TDR and Tensiometer takes place right before and exactly after each main test. In the model slope of $40^{\circ}$, the water content and matric suction sensors were installed and measured in four locations (Fig. 5a).

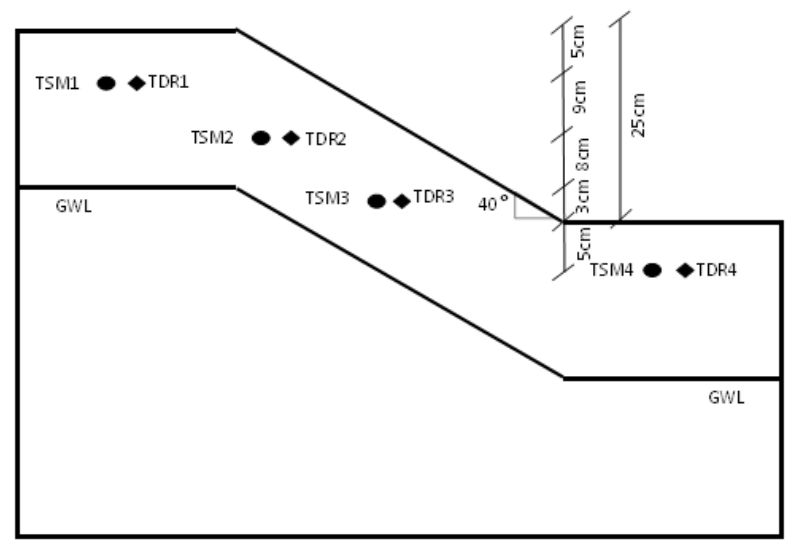

(a)

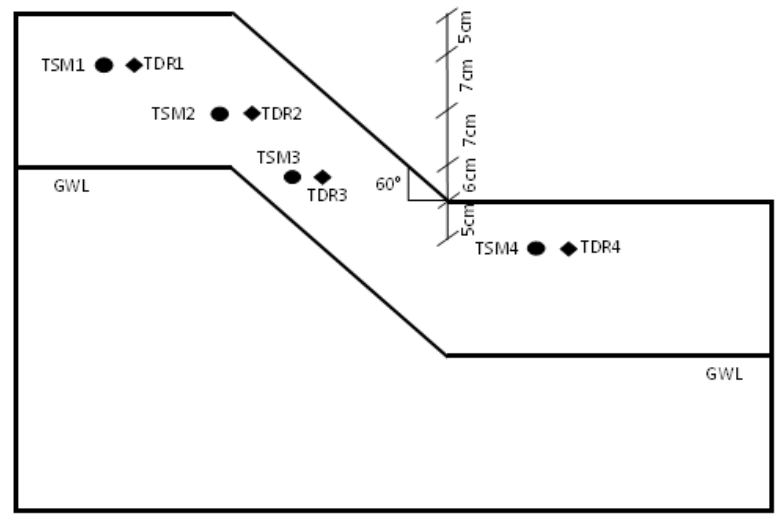

(b)

Fig. 5. The arrangement of TSM and TDR for $40^{\circ}$ slope (b) The arrangement of TSM and TDR for $60^{\circ}$ slope.

TSM1 and TDR1 was placed $20 \mathrm{~cm}$ above the slope toe and $5 \mathrm{~cm}$ from the top of the slope, where the rainfall seepage occurs. TSM2 and TDR2 was place $14 \mathrm{~cm}$ from the top of the slope and sensors TSM3 and TDR3 were place $22 \mathrm{~cm}$ from the top of the slope lastly TSM4 and TDR4 were placed $5 \mathrm{~cm}$ below of the slope toe. In the model slope of $60^{\circ}$ inclination (Fig 5b), TSM1 and TDR1 was placed $20 \mathrm{~cm}$ above the slope toe and $5 \mathrm{~cm}$ from the top of the slope. Meanwhile, TSM2 and TDR2 was placed $12 \mathrm{~cm}$ from the top of the slope, then TSM3 and TDR 3 were placed $6 \mathrm{~cm}$ above the slope toe lastly TDM4 and TDR 4 were place $5 \mathrm{~cm}$ below the slope toe. A digital camera was also used to monitor and investigate the deformation.

\section{Results and discussions}

\subsection{Rainfall data analysis}

\subsubsection{Direct adoption}

According to the 2016 Annual Report from the Department of Meteorology (Malaysia), the highest 
rainfall intensity is recorded at $119 \mathrm{~mm} / \mathrm{h}$ [9]. This intensity is recorded at Kuching (Sarawak) on 3rd January 2016, with massive floods during that period. Such high intensity is favourable due to the extreme conditions occurring in this area during that period.

\subsubsection{Rainfall analysis}

The hyetograph plotted in Figure 6 shows the daily rainfall as a function of the daily rainfall intensity. Based on the analysis, few peaks or higher rainfall intensities in a certain day can be identified throughout the season, revealing that a few high-intensity-rainfall events occur during this season. However, there is a single peak of data that corresponds to the highest daily rainfall intensity on 10th October 2016, indicating that there is a high probability of recording the highest hourly rainfall intensity on this day.

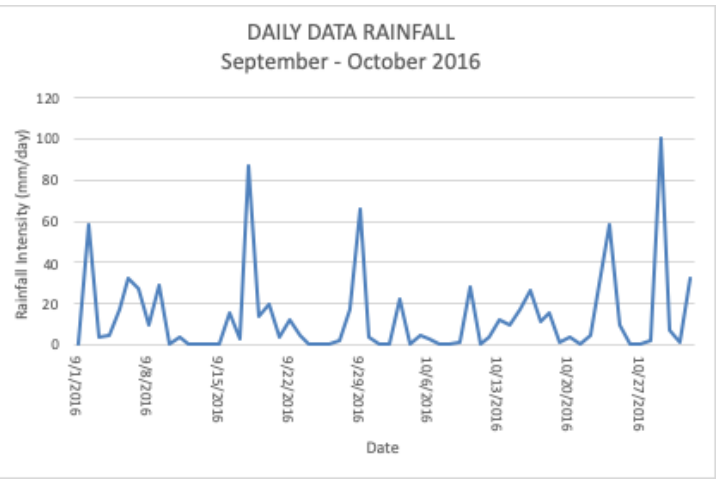

Fig. 6. Daily rainfall hyetograph for the 2016 NEM period.

High daily rainfall is related to the cumulative rainfall intensity that exhibits a lower hourly rainfall intensity, but for a prolonged period. This is also known as the precedent effect where the cycle of rainfall within the period is repetitive and causes the rainfall hyetograph to peak at a daily rainfall intensity. To obtain the extreme hourly rainfall intensity and eliminate the probability of the precedent effect, another hyetograph is plotted using the hourly rainfall intensity for the 10th October reading. The hyetograph exhibits a single highest peak for the hourly rainfall intensity (Figure 7), indicating that the rainfall pattern during that day is intense and that its duration is short.

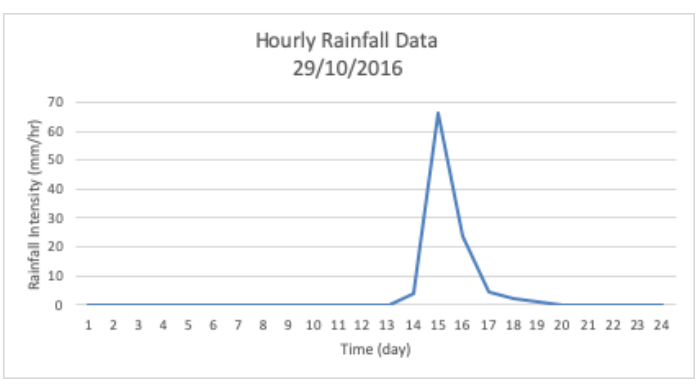

Fig. 7. Hourly rainfall hyetograph for 10th October 2016.
To obtain the highest hourly rainfall intensity, the time step is shifted every $5 \mathrm{~min}$, which would produce a lag of 5 min for every reading, leading to the change in the hourly rainfall intensity (Figure 8 ). The highest hourly rainfall intensity is recorded at $80 \mathrm{~mm} / \mathrm{h}$.

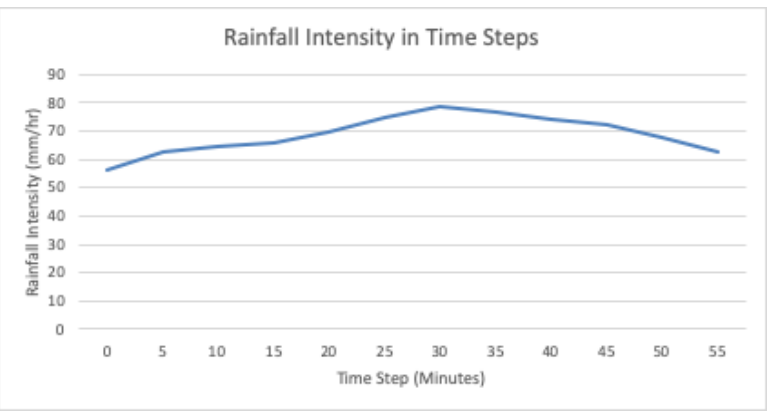

Fig. 8. Rainfall intensity in time-step shift.

\subsection{Physical modelling}

To investigate the effect of the extreme rainfall on the slope stability, the physical model is used to simulate the situation. In this study, four cases are established with slope inclination angles of $40^{\circ}$ and $60^{\circ}$ with rainfall intensities of $120 \mathrm{~mm} / \mathrm{h}$ (Table 2). Figures 9 to 14 show the simulations conducted by the measurement of the matric suction and volumetric water content, which provide insights into the slope condition during the occurrence of failures.

Table 2. Test program.

\begin{tabular}{|c|c|}
\hline Case & Description \\
\hline 1 & $\begin{array}{c}\text { Rainfall intensity of } 120 \mathrm{~mm} / \mathrm{h} \text { and a slope } \\
\text { angle of } 40^{\circ}\end{array}$ \\
\hline 2 & $\begin{array}{c}\text { Rainfall intensity of } 120 \mathrm{~mm} / \mathrm{h} \text { and a slope } \\
\text { angle of } 60^{\circ}\end{array}$ \\
\hline
\end{tabular}

The initial part of the simulation involves the stabilization of the readings for TDR and TSM. Then, the rainfall simulation is performed by subjecting the slope to a rainfall intensity of $120 \mathrm{~mm} / \mathrm{h}$ for a 6 -h period, followed by a $24-\mathrm{h}$ stabilization period. TDR and TSM exhibit similar positions in each case. For TDR and TSM $1 \& 2$, the position is on the upper part of the slope, while for TDR and TSM $3 \& 4$, it is located near the toe on the lower part of the slope. For VMC and MS measurements in all cases, the initial trend during the rainfall simulation revealed an increase in the values of both parameters. However, the reading in TSM 1 revealed an unpredictable reading for a few cases. All readings for VMC and MS in each case decreased after the termination of the rain. The difference in the value and magnitude of VMC for TDR $1 \& 2$ with TDR $3 \& 4$ is related to the position of the slope itself. TDR $3 \& 4$ exhibits a higher initial value and higher difference in the changes due to the increased saturation in that region, corresponding to the increase in the water table and the infiltration of the rain. During the simulation and stabilization period, supervision is performed for any failure occurrence throughout the simulation. The 
supervision includes the total mass wasting and the time for the occurrence of the initial failure. The highest volume of mass wasting is observed for Case 2 simulation, indicating that the slope in Case 2 is the most vulnerable to slope failure.

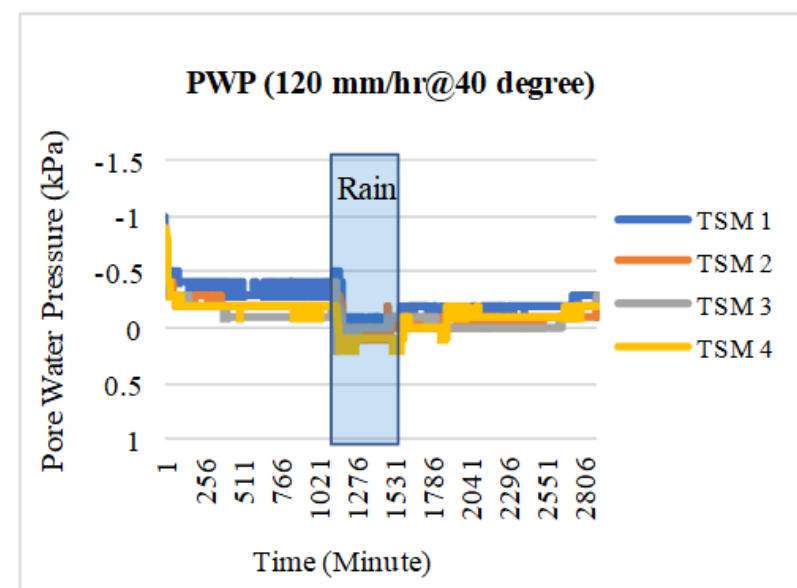

Fig. 9. Pore water pressure results of Case 1: Rainfall intensity of $120 \mathrm{~mm} / \mathrm{hr}$ and a slope angle of $40^{\circ}$.

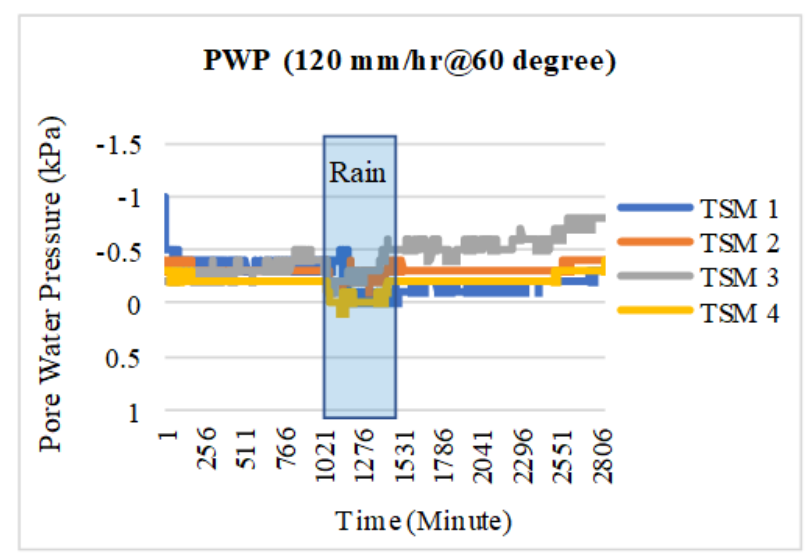

Fig. 10. Pore water pressure results of Case 2: Rainfall intensity of $120 \mathrm{~mm} / \mathrm{hr}$ and a slope angle of $60^{\circ}$.

In case 2 , the $60^{\circ}$ slope angle with an intensity of 120 $\mathrm{mm} / \mathrm{h}$ is the steepest angle and the highest rainfall intensity affording the most severe combination of slope angle and rainfall intensity. Table 3 summarizes the recorded supervision. In case 1 , the total volume of the soil movement is at $4.25 \mathrm{~cm}^{3}$ as seen in Figure 11.

Table 3. Slope failure supervision.

\begin{tabular}{|l|c|c|}
\hline Case & $\begin{array}{c}\text { Volume of Mass } \\
\text { Wasting } \\
\left(\mathbf{c m}^{\mathbf{3}}\right)\end{array}$ & $\begin{array}{c}\text { Time of } \\
\text { failure. } \\
\text { (h) }\end{array}$ \\
\hline Case 1 & 4.25 & 4 \\
\hline Case 2 & 10.0 & 2 \\
\hline
\end{tabular}

The movement of the soil is initiated during the rainfall simulation. After the rainfall simulation start, the first movement of the soil started at fourth hour of the rainfall simulation. However, the volume of the soil that moved is only at $1.75 \mathrm{~cm}^{3}$.

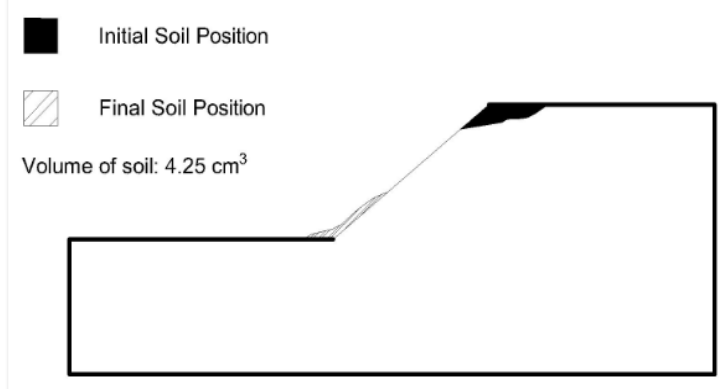

Fig. 11. Pattern of the failure of case 1.

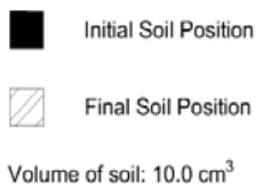

Fig. 12. Pattern of failure for case 2.

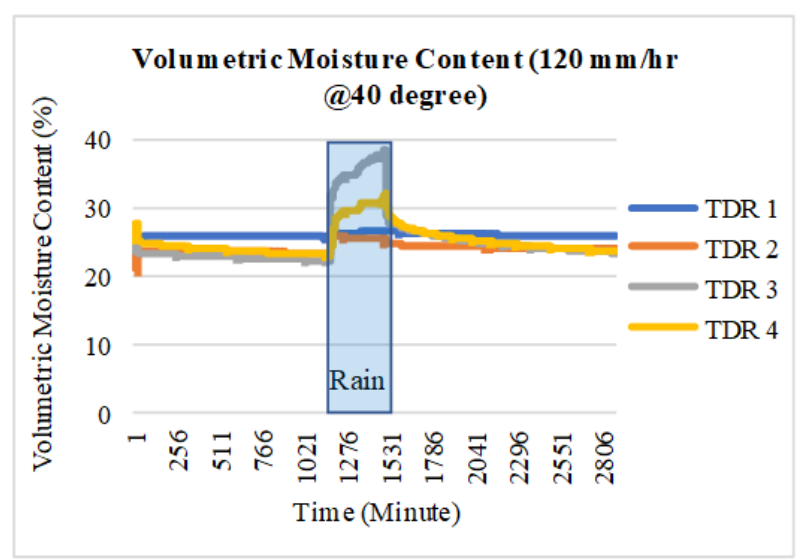

Fig. 13. Volumetric moisture content results of Case 1: Rainfall intensity of $120 \mathrm{~mm} / \mathrm{hr}$ and a slope angle of $40^{\circ}$.

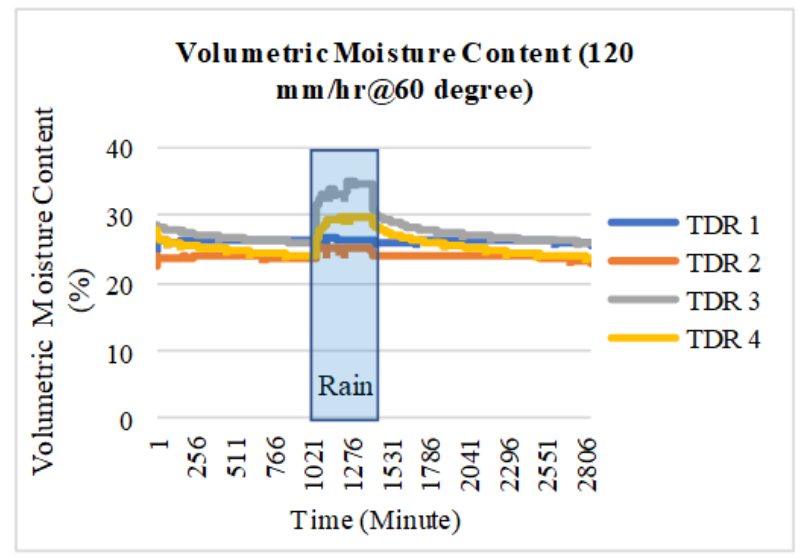

Fig. 14. Volumetric moisture content of Case 2: Rainfall intensity of $120 \mathrm{~mm} / \mathrm{hr}$ and a slope angle of $60^{\circ}$. 
After the first movement of the soil, there is gradual increase in the soil movement. The amount of soil during the movement is not significant. However, at the end of the re-stabilization of the ground water level, the total soil moved from the original position is the highest at $4.25 \mathrm{~cm}^{3}$. This is due to the rearrangement of soil particle that have been disturbed by the dissipated moisture in the pore of the soil. This cause the soil to be rearranged and unable to revert back to the initial arrangement which affecting the stability. Meanwhile, in case 2 , the total volume of the soil movement is at 10.0 $\mathrm{cm} 3$ as in Figure 12. The movement of the soil is initiated during the rainfall simulation. After the rainfall simulation start, the first movement of the soil started at second hour of the rainfall simulation. However, the volume of the soil that moved is only at $5.7 \mathrm{~cm}^{3}$. After the first movement of the soil, there is gradual increase in the soil movement. The amount of soil during the movement is not significant. However, at the end of phase 3 which is the re-stabilization of the ground water level, the total soil moved from the original position is the highest at $10.0 \mathrm{~cm} 3$. The VMC and moisture content of the slope at the moment has dropped. This is due to the rearrangement of soil particle that have been disturbed by the dissipated moisture in the pore of the soil. This cause the soil to be rearranged and unable to revert back to the initial arrangement which affecting the stability.

\section{Conclusion}

This study is conducted to investigate the effect of the extreme rainfall intensity on the slope stability by physical-based modelling. A series of cases are conducted with the variation of the slope inclination angle and rainfall intensity to examine the variation in the parameters and results obtained.

Based on the two selected rainfall intensities, a series of cases are modelled by physical-based modelling. The variation of saturation is determined through the VMC and matric suction measurement within the slope. VMC and matric suction are measured by placing four tensiometers and four TDR within the slope. The measurement of VMC and matric suction revealed that there is an increase in saturation within the slope during the occurrence of the rainfall simulation and decrease after the end of the simulation. However, there is a difference in the magnitude of saturation increase depending on the measurement position. The variation in the saturation level within the slope during the rainfall simulation is determined where all the cases exhibit a similar saturation trend via the VMC measurement.

\section{Acknowledgements}

The authors would like to thank Universiti Sains Malaysia for sponsoring this research project under research grant no. USM(RU) 1001/PAWAM/814246 and Universiti Teknologi Malaysia under the grant USM304/PAWAM/6050407/U107.

\section{References}

1. F. T. Tangang, L. Juneng, E. Salimun, K. Sei, \& M. Halimatun. Sains. Malays., 41(11), 1355-1366 (2012)

2. J. Suhaila, A. A. Jemain. Theor. Appl. Climatol., 108, 235-245 (2012)

3. H. I. Ling, M. H. Wu, D. Leshchinsky, \& B. Leshchinsky. J. Geotech. Geoenviron. 135(6), 758767 (2009)

4. A. Tohari, M. Nishigaki, \& M. Komatsu, (2007). J. Geotech. Geoenviron. 133(5), 575-587 (2007)

5. I. Abudi, G. Carmi, \& P. Berliner, (2012). J. Hydrol. 454, 76-81 (2012)

6. S. N. Mhaske, K. Pathak, \& A. Basak, Catena, 172, 408-420 (2019)

7. M. L. Yakubu, Z. Yusop, \& M. A. Fulazzaky, Hydrolog. Sci. J. 61(5), 944-951 (2016)

8. M. Azmi, S. A. M. Yusoff, M. H. Ramli, \& M. A. Hezmi,. J. Geotech. Eng. 21, 6987-6997 (2016)

9. Meteorology, M. D. O. 2016. 2016 Annual Report Department of Meteorology 2016 ed. Malaysia: Department of Meteorology. 